\title{
Democratic group cognition
}

\author{
Article
}

Accepted Version

Lepoutre, M. (2020) Democratic group cognition. Philosophy \& Public Affairs, 48 (1). pp. 40-78. ISSN 1088-4963 doi: https://doi.org/10.1111/papa.12157 Available at https://centaur.reading.ac.uk/96657/

It is advisable to refer to the publisher's version if you intend to cite from the work. See Guidance on citing.

To link to this article DOI: http://dx.doi.org/10.1111/papa.12157

Publisher: Wiley

All outputs in CentAUR are protected by Intellectual Property Rights law, including copyright law. Copyright and IPR is retained by the creators or other copyright holders. Terms and conditions for use of this material are defined in the End User Agreement.

\section{www.reading.ac.uk/centaur}

\section{CentAUR}

Central Archive at the University of Reading

Reading's research outputs online 


\title{
DEMOCRATIC GROUP COGNITION
}

\author{
Maxime Lepoutre \\ Accepted at Philosophy and Public Affairs \\ Final version here.
}

\section{Introduction}

Citizens of contemporary democracies are famously uninformed about politics. They typically know little about who their representatives are, what policies those representatives support, or how the political system works. ${ }^{1}$ Social scientists and political philosophers alike often worry that this jeopardizes the normative ideal of democracy. Democracy matters, in significant part, as a way of holding policy-makers accountable to the interests and concerns of citizens. But, the argument continues, citizens cannot hold policy-makers accountable if they are woefully uninformed. ${ }^{2}$

A common response to this pessimistic narrative insists that citizens need not know these facts about politics to hold policy-makers accountable. Instead, they can take information shortcuts. That is, citizens can form reliable political judgments by deliberating with those who are more informed than they are, ${ }^{3}$ or simply deferring to their advice concerning which politicians, parties, or policies they should support. ${ }^{4}$

However, this response assumes that when people seek out advice, they are trying to form accurate or reliable political judgments. But there is ample evidence suggesting that, when it comes to politics, people simply accept whatever their social group tells them to believe. Indeed, the way people go about forming political judgments is deeply shaped by group affiliations such as their race, gender, ethnicity, or party. This, critics argue, indicates that citizens are motivated not so much by the desire to form accurate political judgments, as by the desire to satisfy their emotionally charged group loyalties. In politics, it would appear, people process information less like scientists-who seek the truth - and more like sports fans-who embrace whatever views will show their team in the best light. In turn, if people acquire information in a way that is unrelated to the truth, their political judgments seem ill-suited to reliably holding policy-makers accountable. Thus, the democratic ideal, with its emphasis on accountability to the people, seems to be

For helpful feedback and discussion of previous drafts, I am grateful to Heather Battaly, Matthias Brinkmann, Karamvir Chadha-Day, Charlie Crerar, Joanna Demaree-Cotton, Matt Dougherty, Cécile Fabre, Stephen John, Cécile Laborde, Michael Lynch, Ruairi Macguire, Cathy Mason, Louise RichardsonSelf, Elise Rouméas, Jay Ruckelshaus, Bernhard Salow, Tamas Szigeti, Anthony Taylor, Lynne Tirrell, Lani Watson, Ralph Weir, and Andreas Wiedemann, as well as to audiences at the UConn Language and Power Workshop and UConn Humanities Institute. This research was generously supported by a grant from the John Templeton Foundation. The opinions expressed in this publication are those of the author and do not necessarily reflect the views of the John Templeton Foundation.

${ }^{1}$ Ilya Somin, Democracy and Political Ignorance (Stanford: Stanford University Press, 2013), chap. 1; Christopher Achen and Larry Bartels, Democracy for Realists (Princeton: Princeton University Press, 2016), chaps. 2-4.

2 See, e.g., Somin, Democracy and Political Ignorance; Achen and Bartels, Democracy for Realists; Jason Brennan, Against Democracy (Princeton: Princeton University Press, 2016).

${ }^{3}$ E.g., Thomas Christiano, "Rational Deliberation among Experts and Citizens," in Deliberative Systems, ed. John Parkinson and Jane Mansbridge (Cambridge: Cambridge University Press, 2012), 27-51; Hélène Landemore, Democratic Reason (Princeton: Princeton University Press, 2013).

4 E.g., Arthur Lupia and Mathew McCubbins, The Democratic Dilemma (Cambridge: Cambridge University Press, 1998); Elizabeth Anderson, "Democracy, Public Policy, and Lay Assessments of Scientific Testimony," Episteme 8 (2011): 144-64. 
in tension with deep-seated facts about human psychology. ${ }^{5}$ In this light, Christopher Achen and Larry Bartels conclude that "the history of democratic thought [...] is marked by an addiction to romantic theories" of human nature. ${ }^{6}$ Jason Brennan goes further, and contends that this problem warrants abandoning democracy altogether. ${ }^{7}$

The pervasive influence of group attachments on political judgments - or 'group cognition'-seems troubling, particularly in this era of group-based division and polarization. Nevertheless, I will argue that group cognition in fact need not be fatal to the democratic ideal. On the contrary: under the right conditions, group cognition can be reconciled with the democratic ideal, such that it contributes positively to democracy and democratic accountability. The concerns outlined above fail to appreciate this point, in part, because they overlook two important developments in democratic theory: the emphasis on perspectival representation; and the systemic approach to deliberation.

This, to be clear, remains a qualified defense of group cognition. I am not arguing that group cognition is never a problem for democratic governance; nor even that it is not currently a problem for contemporary democracies. Instead, as I will emphasize throughout, specific background social conditions must obtain for group cognition to support democratic accountability. When they do not, group cognition can impair, rather than advance, the democratic process.

Yet, qualified though it may be, this conclusion remains crucially important. First, it gives us a clearer diagnosis of the problems afflicting contemporary democratic politics. It locates the problems of contemporary democracies, less in inalterable facts about the importance of group identity to human beings, and more in social conditions that are ultimately contingent. Accordingly, the problem is not that the democratic ideal, with its emphasis on accountable government, necessarily sits in tension with human psychology. This diagnosis, in turn, is action-guiding. By clarifying the conditions under which group cognition can be a key ingredient in democracy, it highlights tractable strategies for reconciling group cognition and democratic accountability in real-world conditions. These strategies are arduous, to be sure. Nonetheless, our energies are better spent tackling contingent social conditions than the democratic ideal itself.

My argument will proceed as follows. After outlining why the influence of social group membership on political judgment seems problematic (Section 2), I contend that this phenomenon can, under the right conditions, be made to work for democratic accountability. To begin, drawing on influential theories of democratic representation, I suggest that group membership is partly defined by epistemically significant social perspectives. Consequently, group membership constitutes a useful heuristic for determining what policies or politicians one should support (Section 3).

I then consider two difficulties with this argument. Firstly, in a particular domain where group cognition occurs - the domain of politically relevant technical facts-group perspectives do not seem epistemically relevant (Section 4). Secondly, some social perspectives, because they contain distortions, risk leading to political dogmatism (Section 5). The first difficulty, I suggest, neglects the role of normative judgments in testimony regarding scientific or otherwise technical matters. As for the second, it overlooks the systemic conception of democratic deliberation. The upshot, I argue, is this: even though 'technical' and 'dogmatic' forms of group cognition do sometimes impair

\footnotetext{
${ }^{5}$ See, e.g., Dan Kahan, "The Politically Motivated Reasoning Paradigm, Part 1," in Emerging Trends in the Social and Behavioral Sciences (Hoboken: Wiley, 2015), 1-16; Achen and Bartels, Democracy for Realists, chaps. 8-10; Somin, Democracy and Political Ignorance, chap. 3; Brennan, Against Democracy, chap. 2.

${ }^{6}$ Achen and Bartels, Democracy for Realists, 20.

${ }^{7}$ Brennan, Against Democracy, chap. 8.
} 
democratic processes, this need not be the case. Both, under the right conditions, can be made to promote rather than impede democratic accountability.

\section{The Problem of Group Cognition 2.1. Group Cognition}

People form political judgments - judgments about what politicians and policies they should support - in a way that is deeply influenced by their social group attachments. In recent years, this observation has most influentially been articulated by Achen and Bartels, who assert that "for most people, most of the time, party and group loyalties are the primary drivers of vote choice". 8

Typically, social group attachments shape people's political judgments indirectly: they first shape people's party affiliation, which later influences their judgments concerning policies and politicians. ${ }^{9}$ For instance, Achen and Bartels find that, in the New Deal era, the main reason why Boston Jews joined the Democratic Party had little to do with domestic or foreign policy. Instead, it was fundamentally ethnic: it was a response to the fact that Jews had begun acquiring greater status within the Democratic Party. ${ }^{10}$ Similarly, they argue that "racial and regional identity was the more important factor" underpinning Southern realignment, whereby Southern whites massively migrated to the Republican Party from the 1950s onwards. "Southern whites viewed the parties primarily as collections of social groups, not as packages of policy positions": in light of increasing black American mobilization within the Democratic Party, Southern whites left because they no longer perceived it as the party for 'people like them'. Only later did their policy views start to conform to the Republican Party's. ${ }^{11}$ A final illustrative example concerns the Tea Party. Drawing on extensive interview data, Katherine Cramer suggests that Tea Party support is driven, less by antecedent policy preferences - indeed, Tea Party policies sometimes seem paradoxically opposed to the policies favored by rural white Americans - and more by Tea Party politicians' ability to present themselves as identifying with, and coming from, rural white America. ${ }^{12}$

That being said, the influence of social groups on political judgment is not always mediated by partisanship, and it can sometimes run against existing party affiliations. For example, Achen and Bartels observe that gender identity had a deep influence on Americans' judgments about abortion in the 1980s, and specifically on whether those judgments conformed to party lines. While men altered their views on abortion to adhere to party lines, women did not. Instead, women predominantly "gravitate[d] to the party sharing their view about abortion". ${ }^{3}$

The main point is this: either via their influence on party affiliation, or more directly, social group attachments profoundly shape people's political judgments. Why is this problematic?

\footnotetext{
${ }^{8}$ Achen and Bartels, Democracy for Realists, 272. See also: Somin, Democracy and Political Ignorance, chap. 3; Leonie Huddy, Lilliana Mason, and Lene Aaroe, "Expressive Partisanship," American Political Science Review 109 (2015): 1-17.

${ }^{9}$ Achen and Bartels, Democracy for Realists, chap. 9-10.

${ }^{10}$ Ibid., 40.

${ }^{11}$ Ibid., 253; see also 246-264.

${ }^{12}$ Katherine Cramer, The Politics of Resentment (Chicago: Chicago University Press, 2016), 184-203.

${ }^{13}$ Achen and Bartels, Democracy for Realists, 17.
} 


\subsection{The Epistemic Irrelevance of Groups}

The objection, briefly put, is that social group attachments are not an epistemically reliable indicator of which policies, parties, or political representatives are desirable. In particular, the fact that someone belongs to our social group does not give us a reason to believe that their judgments about political matters are trustworthy. Accordingly, shared group membership does not give us an epistemic reason to defer to someone's views about parties or policies. Nor, relatedly, does it give us a reason to believe that they would make a good political representative.

What drives this objection is an account of what social groups are. Often, critics of group cognition characterize social groups extensionally, by offering examples of such groups. ${ }^{14}$ As shown above, the examples that come up most often are race, gender, ethnicity, regional attachments, and party affiliation. However, this extensional characterization only postpones the key question: what is it about these groups that makes them an inadequate epistemic indicator of what policies to support and of whose political judgment to trust?

Although Achen and Bartels do not commit to a systematic intensional account of social groups - an account of what it means for a set of people to constitute a social group - they do offer some indications that shed light on the above objection. First, they observe that social group memberships tend to originate in arbitrary ways. If group memberships resulted from reasoned choices that were based on one's prior policy preferences or ideological commitments, then their influence on political judgments might seem epistemically respectable. Indeed, if this were the case, the fact that someone belongs to one's group would be a sign that they concur with judgments that one antecedently takes to be sound. This, in turn, would constitute a pro tanto reason to believe that their judgment is trustworthy. However, Achen and Bartels insist that this is not the case. Social group memberships such as race or ethnicity are typically unchosen. And even insofar as they can be chosen, they tend to be chosen in ways that are in an important sense arbitrary: people's grounds for joining groups are generally not their prior reasoned judgments about policy or ideology. ${ }^{15}$ Because of their arbitrary origin, then, group attachments do not give us epistemic reasons in the way that groups formed on the basis of reasoned policy or ideology judgments would.

Second, group attachments are emotional in nature. Alongside other critics of group cognition, Achen and Bartels emphasize "the powerful role of emotion rather than reason in directing group activity". ${ }^{16}$ The idea is that group attachments invite people to think about politics in a way that is charged with emotion, rather than based on rational thought or logic. And since rational thought and logic are the paradigmatic epistemically reliable ways of forming judgments, this suggests that group cognition is not epistemically reliable. It aims not at producing accurate political judgments, but rather at satisfying the emotional dispositions that define one's group identity.

One might object that this account, however plausible it may be for racial, gender, or ethnic groups, is implausible as a characterization of party affiliation. According to Regina Rini, political parties reflect people's moral and political values, or ideology. If people choose their party based on reasoned ideological judgments, and if party affiliation

\footnotetext{
${ }^{14}$ Ibid., chaps. 8-10; Kahan, "The Politically Motivated Reasoning Paradigm, Part 1," 11-12.

${ }^{15}$ Achen and Bartels, Democracy for Realists, 220-23.

${ }^{16}$ Ibid., 215; and 228, 255. See also: Kahan, "The Politically Motivated Reasoning Paradigm, Part 1," 2-

3; Huddy, Mason, and Aaroe, "Expressive Partisanship," 3-4; Brennan, Against Democracy, 12; Somin,

Democracy and Political Ignorance, 87.
} 
later shapes their political judgments, then one of the main forms of group cognitionnamely, party-based cognition - might be epistemically useful after all. ${ }^{17}$

However, this response neglects the empirical reality of how party affiliations actually form. Political elites do often choose parties based on prior reasoned judgments about ideology and policy. But Achen and Bartels are adamant that most people do not: ideological commitments are "more often an effect of partisanship than its cause". ${ }^{18}$ As we have already seen in 2.1, partisan affiliation instead habitually results from people's prior social group attachments, such as their race, gender, ethnicity, or regional identity. Thus, "partisanship is both a form of social identity and, in significant part, a product of social identity". 19

Hence, party affiliation too seems vulnerable to the above concerns. If partisanship derives from group loyalties that arise arbitrarily, then its origin also seems, at bottom, to be arbitrary. Moreover, if the social group attachments that undergird party loyalty are emotional in nature, then party loyalty too is presumably emotional in nature. This is indeed how Brennan characterizes partisanship: people support political parties in an impassioned way, much as hooligans support sports teams. ${ }^{20}$ So, like other social group attachments, party affiliation appears to be an epistemically inadequate basis for forming political judgments.

\subsection{The Depth of the Problem}

In sum, the problem of group cognition runs as follows. Voters use social group membership as a basis for forming judgments about parties, politicians, and policies. But social group membership is not an epistemically reliable basis for forming political judgments. So, voters form political judgments in an epistemically unreliable way.

This, in turn, seems troubling for democratic accountability. For political decisionmaking to be accountable to the interests and concerns of the demos, citizens must form their political judgments in a way that reliably identifies what policies or politicians would serve their interests and concerns. If, instead, they base their judgments on epistemically arbitrary cues, there is no reason to think that this will happen. "From the viewpoint of governmental representativeness and accountability", Achen and Bartels therefore conclude, "election outcomes are essentially random." 21

Prior to criticizing this argument, it is worth emphasizing why, if successful, it would constitute a distinctively powerful challenge to democratic theory. First, it is not merely about how politically uninformed people are. Rather, it criticizes the process through which people seek information and form political judgments. Hence, this problem forestalls the intuitive reply that even if most people are currently uninformed, they can readily learn more by seeking out political advice.

Second, and relatedly, group cognition is not confined to those who are particularly uninformed about politics. On the contrary, it affects even unusually well-informed and politically engaged people. ${ }^{22}$ So, the problem at hand is more pervasive than criticisms of democracy that merely focus on how uninformed citizens are.

\footnotetext{
${ }^{17}$ Regina Rini, "Fake News and Partisan Epistemology,” Kennedy Institute of Ethics Journal 27 (2017): 51.

18 Achen and Bartels, Democracy for Realists, 234.

${ }^{19}$ Ibid., 266.

${ }^{20}$ Brennan, Against Democracy, chap. 2.

${ }^{21}$ Achen and Bartels, Democracy for Realists, 176.

22 Ibid., 268.
} 
Third, group cognition seems to be deeply rooted in human psychology. For Achen and Bartels, "human nature makes group attachments powerful forces in political thinking". ${ }^{23}$ This matters because, if group cognition is part of human nature, and if this way of forming political judgments is inconsistent with democratic accountability, then there might seem to be no way-short of altering human nature itself — of salvaging democratic accountability.

Finally, the problem of group cognition is unlikely to be solved by appealing to aggregative mechanisms. A popular response to the fact that individual citizens sometimes make poor political judgments points to aggregative mechanisms: aggregating many individual judgments through majority rule can, under the right conditions, yield decisions that are more reliable than any individual citizen is. However, the most influential such argument, which derives from the Condorcet Jury Theorem, requires that individual citizens vote independently of one another. This condition is clearly violated if citizens' political judgments are deeply shaped by their group attachments.

Thus, if sound, the problem of group cognition is extremely forceful. One might challenge its empirical premise-that social group identities deeply shape political judgments. However, I will accept this premise for the sake of argument. Instead, I will argue that social group membership can in fact be an epistemically useful basis for forming political judgments, such that group cognition can be reconciled with the ideal of democratic accountability.

\section{Group Cognition Inside the Democratic Ideal 3.1. Groups and Social Perspectives}

In suggesting that the democratic ideal is out of touch with the reality of group cognition, critics overlook an influential tradition of democratic theory, which gives social groups a central role in the democratic process. Specifically, according to some democratic theorists, there are strong reasons for voters to be represented by members of their own social groups. Jane Mansbridge, for instance, replies "Yes" to the question "Should blacks represent blacks and women represent women?"24 Similarly, Iris Marion Young advocates group representation to ensure that distinctive perspectives and marginalized voices are heard. ${ }^{25}$

This tradition, I will argue, reveals that group cognition does have epistemic value, in virtue of which it can be a positive ingredient in the ideal of democratic accountability. Our question, then, is this: in what respects might social group attachments be epistemically relevant to forming political judgments? Why, in particular, does the fact that someone comes from one's social group give one reason to believe that their judgment is reliable or trustworthy?

By articulating the notion of a social perspective, Young's discussion of group representation helps address these questions. Part of what it means to belong to a social group defined along axes such as race, gender, class or ethnicity, according to Young, is that one occupies a distinctive position in the social structure. This, in turn, means that one is subjected to a distinctive set of social constraints and enablements by the laws, norms, and physical infrastructure that constitute the social context. So, a social group differs from a random set of people in that its members "experience similar constraints or

\footnotetext{
${ }^{23}$ Ibid., 232, emphasis added.

24 Jane Mansbridge, "Should Blacks Represent Blacks and Women Represent Women? A Contingent

'Yes,"” Journal of Politics 61 (1999): 628-57.

${ }^{25}$ Iris Marion Young, Inclusion and Democracy (Oxford: Oxford University Press, 2000), chap. 4.
} 
enablements". ${ }^{26}$ The social group 'women', on this view, is partly defined by exposure to a distinctive set of shared constraints, such as the expectation that one shoulder the lion's share of childcare, and disproportionate subjection to harassment in the workplace. Likewise, as Ann Cudd explains, to be a middle-class black man is, in part, persistently to encounter different constraints and enablements than a middle-class white man might: "the middle-class black is likely to be followed by store workers, he is likely to be harassed by police in white neighborhoods or if seen driving an expensive car", and so on. ${ }^{27}$

Because they experience group-specific constraints and enablements, members of a social group have distinctive knowledge that members of other groups may lack. Young calls "social perspective" the particular way of looking at things which results from having this group-specific knowledge. ${ }^{28}$ A group's social perspective involves, firstly, a descriptive component: knowledge of particular facts about society that one gleans from one's group-specific experiences of constraint and enablement. But social perspectives also involve a normative component, which falls out of the descriptive component. Because certain societal constraints are more salient to members of a particular social group, they are more likely to be objects of concern to these members. These constraints are more likely to be in the foreground of their thinking, as problems to be addressed. ${ }^{29}$ For example, because micro-aggressions are more visible to a middle-class black man than to a middle-class white man, they are more likely to be at the forefront of the former's concerns. Similarly, in virtue of having greater personal experience of sexual harassment, women might not only know more about this issue, but also take it more seriously as a problem to be tackled.

The upshot, for Young, is that it is epistemically reasonable to give preference to representatives who come from one's own social group. The fact that someone comes from one's group is an indicator that they share a relevant social perspective: they have knowledge of social constraints that one experiences, and are more likely than others to share one's normative concerns relating to those constraints. Consequently, shared group membership gives one a pro tanto epistemic reason to think that their political judgment is trustworthy - and, by extension, that they would make a good representative. Indeed, one has reason to believe that, as a representative, they will reason about policy issues in light of descriptive and normative considerations one deems important. For example, Young notes, the fact that a given candidate is a woman is a reason to believe that she is more likely to appreciate the pervasiveness and seriousness of sexual harassment. ${ }^{30}$ Accordingly, Mansbridge observes, "it is not surprising [...] that women legislators have usually been the ones to bring these issues [of harassment] to the legislative table". ${ }^{31}$

The point, however, is not restricted to judgments about political representatives. If shared group membership is a pro tanto reason to trust someone's political judgment, then the party affiliation of members of one's group constitutes a valuable heuristic for deciding which party to support. Put differently, the fact that members of one's social group disproportionately belong to or support party $\mathrm{X}$ might well constitute a pro tanto epistemic reason to support $X$. What this fact signals, in short, is that $X$ may be distinctively attuned to group-specific constraints that one judges to be politically important. Hence, Achen and Bartels's observation that social group attachments drive

\footnotetext{
${ }^{26}$ Ibid., 95-100.

${ }^{27}$ Ann Cudd, Analyzing Oppression (Oxford: Oxford University Press, 2006), 44-45.

28 Young, Inclusion and Democracy, 136-37.

${ }^{29}$ Ibid., 114-117.

${ }^{30}$ Ibid., 140.

${ }^{31}$ Mansbridge, "Should Blacks Represent Blacks and Women Represent Women?" 647.
} 
party affiliation may not be so troubling after all. When Boston Jews saw that Jews were well represented in the Democratic Party, they learned that members of the Democratic Party shared many of their experiences of social constraint, and were more likely to attend to associated concerns. Likewise with the Tea Party. When its leaders indicate that they come from rural communities, they thereby signal an affinity with the perspective of rural inhabitants - what Cramer famously calls "rural consciousness". This, Cramer suggests, might involve sharing experiences of rising rural joblessness, of rural jobs' physical toll, or of having one's lifestyle derided or vilified. ${ }^{32}$ This affinity with the social constraints that constitute rural consciousness gives rural inhabitants a reason to trust them.

Social group membership can also more directly inform judgments about policy. Indeed, the descriptive and normative concerns contained in group-specific perspectives can sometimes bear directly on policy matters. This elucidates another case Achen and Bartels worry about: the influence of gender on judgments about abortion. If women have relevant experiences that men lack (e.g., experiences of childbearing) and if the proposed legislation would remove constraints that men do not face (e.g., constraints on what women do with their bodies) then it is neither surprising nor epistemically troubling that women formed their judgments about abortion differently than men. They had relevant experiential knowledge, which men lacked, that bore directly on the issue.

Now, at first sight, this account of why social group membership constitutes an epistemically useful basis for forming political judgments may seem empirically dubious. The policy views of political representatives and parties often differ from the policy preferences of citizens who vote for them. ${ }^{33}$ But if shared group membership indicates a shared social perspective, and if a social perspective contains valuable knowledge regarding the constraints a given group experiences, one might expect the opposite: namely, that the policy judgments of party elites and representatives would closely resemble those of voters from the same group.

In fact, this observation is consistent with the account I have offered. People can share an epistemically valuable social perspective yet still disagree in their policy views. ${ }^{34}$ One reason for this is that the experiential knowledge contained in a group's perspective, though relevant to policy decisions, is often insufficient for identifying fitting policies. Often, the descriptive information contained in a group's perspective helps to identify important problems that need addressing (e.g., rural joblessness). Yet to determine which specific policy would best respond to these problems, various kinds of political information are frequently also needed: information about the causal effectiveness of different policies at solving the problem, about their financial cost, about their political feasibility, and so on. Voters usually have far less knowledge of this kind than party elites. ${ }^{35}$ Accordingly, even if voters and the elites representing them share an epistemically valuable social perspective, elites may come to different policy judgments based on this perspective because they have greater political knowledge. ${ }^{36}$

\footnotetext{
${ }^{32}$ Cramer, The Politics of Resentment, 61-84.

${ }^{33}$ Achen and Bartels, Democracy for Realists, 48; Cramer, The Politics of Resentment, 149-152.

${ }^{34}$ Young, Inclusion and Democracy, 137-138.

${ }^{35}$ Somin, Democracy and Political Ignorance, chap. 1.

${ }^{36}$ This information-related explanation for the policy divergence between voters and elites makes sense of two other empirical observations reported by Achen and Bartels (Democracy for Realists, 259, 261, 268, 284-296). First, it successfully predicts that more politically knowledgeable voters will be more closely aligned with their parties' policy commitments than other voters. Second, it explains why uninformed voters do not simply mimic the policy judgments of their party elites (which would lead their policy views to be closely aligned). Uninformed voters may fail to do so precisely because they are uninformed, and so do not always know their elites' specific policy positions.
} 
Seen in this light, group cognition seems a useful way for politically uninformed voters - the majority of voters - to manage their ignorance. Using social group membership as a heuristic, voters select a party or representative that shares their knowledge of important group-specific social constraints. That party or representative is then tasked with bringing their greater political knowledge to bear on these group-specific concerns. And, crucially, there is evidence that this process is broadly effective at generating responsive policy-making. As mentioned earlier, women legislators have often pioneered legislative change relating to problems that disproportionately affect women, such as sexual harassment. ${ }^{37}$ Moreover, Nicholas Carnes finds that legislators from working-class backgrounds are more likely to support liberal policies, such as social security policies, that respond to working-class concerns. ${ }^{38}$ Similarly, black and Latino representatives are generally more likely to support policies that speak to blacks' or Latinos' group-specific constraints, even when doing so is not electorally advantageous. ${ }^{39}$

Note, finally, that the explanation I have just offered does not mean that group membership cannot sometimes be an epistemically useful basis for directly choosing policies. While group membership typically affects people's political choices via its influence on their partisan identity, we have seen that it sometimes more directly influences policy judgments. This, recall, was historically the case with judgments about abortion. This may seem worrying if, as I have just suggested, voters often lack the political information needed to derive sound policy judgments from their group-specific experiential knowledge (e.g., detailed information about the causal consequences of policies). ${ }^{40}$

The key insight here is that different policy issues vary in how much political information they require. Identifying the best way to eliminate rural joblessness requires significant information about the causal consequences of competing economic policies, which itself hinges on complex technical matters of fact. However, not all policy issues are like this. Disputes relating to abortion often stem less from disagreement about the expected causal consequences of different abortion policies, and more from disagreement about the moral significance of those consequences. Women's group-specific experiential knowledge speaks directly to this latter disagreement. Accordingly, in a case such as this one, the direct influence of group membership on policy judgments may well remain epistemically appropriate.

Still, this points to a potential problem for group cognition. The case of abortion is one where group perspectives are highly relevant to the policy judgments at hand. But there may be policy domains where this is not the case, yet group perspectives nonetheless

\footnotetext{
${ }^{37}$ See note 31.

${ }^{38}$ Nicholas Carnes, White-Collar Government (Chicago: University of Chicago Press, 2013).

${ }^{39}$ See, e.g., Michael Minta, "Legislative Oversight and the Substantive Representation of Black and Latino Interests in Congress," Legislative Studies Quarterly 34 (2009): 193-218; David Broockman, "Black Politicians Are More Intrinsically Motivated to Advance Blacks' Interests," American Journal of Political Science 57 (2013): 521-536.

${ }^{40}$ One might worry that political ignorance also constitutes an obstacle to using group membership as a basis for selecting parties and political representatives. After all, like selecting policies, doing this requires some political knowledge besides the experiential knowledge contained in one's group perspective. With representatives, one needs to know whether a given candidate actually belongs to one's social group. And to determine whether a party is likely to be attuned to one's group perspective, one may need to know whether members of one's group are better represented in this party's ranks than in other parties, or whether opinion leaders from one's group typically support this party. Nevertheless, these informational demands do not seem excessively demanding. To reiterate, the evidence canvassed by Achen and Bartels (Democracy for Realists, chap. 9) shows that shared group membership is a strong predictor of voter support for parties and representatives. So it seems as though voters often succeed in clearing this informational hurdle.
} 
deeply shape people's judgments. It would seem prima facie troubling, for instance, if social group membership directly influenced people's judgments concerning highly technical or esoteric policy issues (such as the expected causal consequences of complex economic policies or of complex environmental processes). In Section 4, I will consider an objection which holds that there is indeed such a domain.

Let us summarize the argument so far. I have argued that social group membership seems an epistemically useful basis for forming political judgments. A group's perspective contains descriptive and normative information regarding society, which is derived from group members' shared experiences of constraint and enablement. Using group membership as a heuristic for forming political judgments can help make policymaking responsive to these group-based descriptive and normative considerations. Thus, far from impeding democratic accountability, group cognition may rather be a way of achieving it: group cognition can help identify which parties, politicians and policies would effectively track the considerations contained in one's group-based social perspective, where these are themselves rooted in epistemically valuable experiences.

\subsection{A Different Conception of Groups?}

My reconciliation of group cognition and the democratic ideal, which depends on the notion of a social perspective, has relied on Young's account of social groups. One might worry that the kinds of social groups Young discusses differ from the kinds of social groups Achen and Bartels discuss. If so, my argument fails: even if groups in Young's sense are epistemically important, people form their political judgments on the basis of a different kind of group membership.

In fact, there are good reasons to think that Young's social groups are broadly equivalent to the social groups involved in group cognition. To begin, Young's conception of social groups is extensionally similar to Achen and Bartels's. Indeed, the core examples of social groups she gives - e.g., race, gender, class, or region-are also examples of groups that shape their members' political judgments.

This extensional equivalence might nonetheless seem imperfect. Achen and Bartels also mention ethnicity and religion (e.g., Judaism, Catholicism) as examples of judgmentshaping group attachments. ${ }^{41}$ These might seem to be cultural groups-groups united by shared values and practices - rather than social groups in Young's sense-groups united by shared experiences of social constraint and enablement. But this apparent mismatch is more apparent than real. As Young observes, cultural groups are often also social groups. ${ }^{42}$ When a specific cultural group, because it is identified as such, comes to encounter common social constraints and enablements, it thereby also becomes a social group. This might happen, say, if Jews or Catholics experience group-specific acts of discrimination, occupy similar jobs, live in similar neighborhoods, or attend similar schools. And this was indeed the case in the United States during much of the twentieth century, where Achen and Bartels's examples are situated. ${ }^{43}$

Young's conception of social groups also seems compatible with Achen and Bartels's intensional characterization of social groups. The first intensional characteristic, recall, is that group memberships typically have an arbitrary origin: they are habitually unchosen; and even when they are chosen, this is generally not on the basis of prior reasoned judgments about ideology or policy. This fits easily with Young's account of social groups. To belong to a social group, for Young, is to be exposed to a particular set of

\footnotetext{
${ }^{41}$ Achen and Bartels, Democracy for Realists, chap. 8.

42 Young, Inclusion and Democracy, 98.

${ }^{43}$ James Davidson and Ralph Pyle, Ranking Faiths (Lanham: Rowman and Littlefield, 2011), chap. 5.
} 
social constraints and enablements. Crucially, Young emphasizes that what particular constraints and enablements one is subjected to is something "over which [one] ha[s] little control", 44 and often a mere "accident of birth". ${ }^{45}$

Hence, we can now appreciate that the problem of group cognition commits the genetic fallacy. From the fact that the origin of social group attachments is arbitraryi.e., not chosen on the basis of sound political judgments - they infer that their nature is arbitrary from the perspective of sound political judgments. But Young's account shows that this is incorrect. Regardless of how randomly one ended up in a particular social position, being in that position remains epistemically relevant to political judgment. This, once more, is because one's social position gives one privileged epistemic access to politically relevant constraints and enablements.

The second intensional characteristic of social groups that drive political judgmentthat they are emotionally charged-might seem more problematic. "Emotional attachments," according to Achen and Bartels, "transcend thinking". ${ }^{46}$ But social group attachments in Young's sense do not transcend thinking. On the contrary, Young emphasizes how group attachments provide descriptive knowledge of social constraints, which in turn enriches normative reasoning about politics. So, one might conclude, social groups in Young's sense cannot be emotionally charged.

This worry depends on the assumption that emotions are divorced from rational thought. However, this is a misconception: emotions have an important cognitive dimension, in virtue of which they contribute fruitfully to reasoning. In particular, philosophers of emotion have widely argued that emotions are sources of salience: they render salient certain properties of the object that they are directed at. As Brun et al. put it, emotions "establish focus on certain aspects of a situation, they act as "spotlights", which "pu[t] some properties of a situation into the foreground". ${ }^{47}$ Different emotions put a spotlight on different kinds of properties. Fear highlights features of our environment that are potentially dangerous; anger focuses our attention on potential sources of injustice; grief makes loss salient to us; and so on. Because they play this varied salience role, emotions have epistemic value. They help us navigate complex environments by drawing our attention to important facts that we may otherwise overlook. In doing so, they enrich the information on the basis of which we reason. ${ }^{48}$

Once emotions are understood as sources of salience, the idea that group attachments are emotionally charged seems intimately connected to Young's idea that groups are characterized by a distinctive social perspective. A group's social perspective, recall, is a way of looking at things that is informed by that group's specific experiences of social constraint. It typically involves having these constraints in the foreground of one's thinking, as problems to be addressed. In short, then, to have a social perspective is partly to experience certain constraints as salient. Hence, we should not be surprised if group attachments involve both a distinctive social perspective and certain emotional dispositions: since emotions are one important way in which we might experience certain social constraints as salient, and since perceiving certain social constraints as salient is part of what it means to have a particular social perspective, a shared social perspective may well manifest itself in shared emotional dispositions.

\footnotetext{
${ }^{44}$ Young, Inclusion and Democracy, 92.

${ }^{45}$ Ibid., 96.

${ }^{46}$ Achen and Bartels, Democracy for Realists, 228.

47 Georg Brun, Ulvi Doguoglu, and Dominique Kuenzle, "Introduction: A New Role for Emotions in Epistemology?," in Epistemology and Emotions, ed. Georg Brun and Dominique Kuenzle (Hampshire: Ashgate, 2008), 18. See also Michael Brady, Emotional Insight (Oxford: Oxford University Press, 2013), 16.

${ }^{48}$ Brady, Emotional Insight, 25.
} 
This point is vividly illustrated in James Baldwin's reflections on what it means to be a black American in the 1960s:

To be a Negro in [America] and to be relatively conscious is to be in a rage almost all of the time [...] Part of that rage is this: it isn't only what is happening to you, but it's what is happening all around you all of the time, in the face of the most extraordinary and criminal indifference ${ }^{49}$

Baldwin posits a tight connection between what it means to be a black American and an emotional experience, the experience of profound anger. In turn, he identifies this anger with the state of being alert to the injustices black Americans are subjected to (being "conscious" of "what is happening all around you"). For Baldwin, then, there is no real contrast between the Youngian social perspective of black Americans - the perspective that arises out of their distinctive experiences of constraint - and black Americans' experience of anger. Rather, black Americans' social perspective is partly realized in their shared experience of anger.

Thus, the kinds of social groups at play in my Youngian argument seem importantly similar to those involved in evidence of group cognition: they often originate arbitrarily; they may well be emotionally charged; and they are drawn along similar axes, such as race, gender, class, region, ethnicity, or religion.

Still, one might worry that my argument only applies to a subset of the groups involved in group cognition. Young's examples of epistemically fruitful social perspectives generally concern groups whose shared experiences involve unfair disadvantage - for example, women, people of color, and working-class groups. But group cognition affects relatively privileged groups as well. As discussed earlier, feelings of white Southern identity led white Southerners to flock to the Republican party from the 1950s onwards. Likewise, during the 1960 US presidential election, the more voters felt a Protestant identity, the more preoccupied they were with John F. Kennedy's Catholic identity. It seems far less obvious that membership in such comparatively privileged groups facilitates access to distinctive politically relevant knowledge. And if these groups do not yield distinctive knowledge, these instances of group cognition may seem devoid of epistemic value.

Privileged perspectives do in fact have some epistemic value. Young herself suggests as much. Even "in a society with white privilege", she insists, "the social perspective of white people is not itself wrong or illegitimate". ${ }^{50}$ The problem is rather that such perspectives "usually dominat[e] the making of many public discussions" to the exclusion of other valuable perspectives. ${ }^{51}$

However, Young does not explain why privileged perspectives remain epistemically valuable. One might find this doubtful. If privilege is constituted by exemption from burdens others face, a privileged group might seem by definition to lack knowledge of social constraints. And even insofar as privileged groups do experience social constraints, one might think that these experiences are not distinctive. Less privileged groups may already experience these constraints, and further constraints besides.

Despite these doubts, there are several reasons to think that privileged groups experience distinctive constraints. Firstly, some genuine constraints are flipsides of a comparatively high status. For instance, because higher education is a marker of middleand upper-middle-class status, student debt is something disproportionately experienced

\footnotetext{
${ }^{49}$ James Baldwin et al., "The Negro in American Culture," CrossCurrents 11 (1961): 205.

${ }^{50}$ Young, Inclusion and Democracy, 146.

${ }^{51}$ Ibid.
} 
by these groups. Another reason relates to segregation. Infamously, contemporary democracies often involve pervasive segregation along the lines of class, race, and ethnicity. Advantaged and disadvantaged social groups tend to live in different residential areas, where they attend different schools and work different jobs. ${ }^{52}$ These different areas frequently face different challenges relating, say, to transportation, housing, or education. Consequently, privileged groups may have distinctive knowledge of the constraints that affect the areas in which they disproportionately reside.

Consider how this last point might apply to the above examples. Since American Protestants and Catholics in the mid-twentieth century tended to live in different neighborhoods, to attend different schools, to visit different hospitals, and to recognize different faith-based moral authorities, ${ }^{53}$ Protestants had a pro tanto reason to believe that a Catholic president would be less attuned than a Protestant president to the constraints they were concerned about. Similar considerations arguably extend to Southern whites. Achen and Bartels report that their political realignment was not explained by negative attitudes towards black Americans, nor by policy judgments relating to racial integration (perhaps surprisingly, Southern whites who left the Democratic Party favored and opposed racial integration in equal measure).$^{54}$ What explained it, they suggest, is rather a sense of affinity with (predominantly white) Southern identity. ${ }^{55}$ And just as the (predominantly white) rural inhabitants interviewed by Cramer faced distinctive challenges relating to the specific place in which they lived and the specific jobs that they occupied, one might surmise that so, too, did Southern whites.

Yet a problem remains: even if privileged perspectives facilitate distinctive knowledge of some important social constraints, these perspectives may also obscure other, likely more important, constraints. While privileged groups may experience problems relating to their relatively high status (such as student debt), they have comparatively little exposure to the greater social problems that affect disadvantaged groups. Relatedly, while segregation may give them distinctive knowledge of their own neighborhoods, it simultaneously conceals other neighborhoods and the out-groups that inhabit them. Thus, even if privileged perspectives have some epistemic value, they may well also involve important distortions.

For example, because of pervasive racial segregation, white Americans are often ignorant of the constraints black Americans face. Elizabeth Anderson has powerfully argued that this group-based ignorance, together with the psychological tendency for ingroup favoritism, facilitates further perspectival distortions. Specifically, it makes white Americans more likely to mistakenly explain black disadvantage in terms of black Americans' inherent dispositions, rather than adverse social circumstances. Consequently, Anderson suggests, white Americans are liable to endorse stigmatizing stereotypes that present black Americans as dispositionally lazy or incompetent. ${ }^{56} \mathrm{~A}$ similar observation holds for the 1960 US election. While the social differences between American Protestants and Catholics may have given Protestants some reasons to think that a Catholic president would be less responsive to their group-specific constraints, it also facilitated ignorance about Catholics. Accordingly, although some Protestant voters offered relatively sophisticated reasons for being wary of Kennedy's Catholicism, many expressed misplaced worries based on negative misperceptions of Catholics. Some, for

\footnotetext{
52 Ibid., chap. 6; Elizabeth Anderson, The Imperative of Integration (Princeton: Princeton University Press, 2010).

${ }^{53}$ Davidson and Pyle, Ranking Faiths, chap. 5.

${ }^{54}$ Achen and Bartels, Democracy for Realists, 251-258.

55 Ibid., 255-257.

${ }^{56}$ Anderson, The Imperative of Integration, 44-50.
} 
instance, held "dark beliefs that Catholicism lay somewhere on the road to Communism". 57

The problem, then, is this. Although privileged group perspectives do involve valuable group-specific knowledge, this epistemic contribution may be counterbalanced or even outweighed by epistemic distortions. We can put the point slightly differently. Although privileged social perspectives yield valid pro tanto epistemic reasons for forming political judgments, those reasons may not be sufficiently strong, all-thingsconsidered, to warrant influencing political judgments so significantly. Insofar as members of privileged groups allow their group perspective to determine their political judgments, they are therefore granting too mисh weight to some politically relevant evidence (that which comes from their group-specific experiences) relative to other evidence (that which their group-specific experiences obscure). Therefore, group cognition makes them behave dogmatically. And, unless it is somehow tempered, this dogmatism leads them to form many inaccurate judgments (e.g., distorted perceptions of out-groups).

Note that this problem, though especially acute with privileged perspectives, is actually not entirely confined to them. For Young, the epistemic benefits of disadvantaged perspectives too may come at an epistemic cost: "they too are liable to bias [...] in overstating the nature of situations, misunderstanding their causes, or laying blame in the wrong place". ${ }^{58}$ While the perspectives of disadvantaged groups are distinctively attuned to very important social problems, they nevertheless experience only part of the social context, and are therefore bound to have blindspots. They may, for instance, overlook urgent problems that other disadvantaged groups experience. For example, although the rural perspective Cramer explores is rightly sensitive to the serious economic difficulties that rural communities face, it also tends to underestimate the economic difficulties encountered in urban areas. Partly because of this blindspot, "rural consciousness" typically involves resentment towards urban dwellers whom it commonly depicts as privileged, undeserving, and arrogant ${ }^{59}$ So, although the problem is arguably more severe with privileged groups (since these tend to overlook more important social constraints) it is not unique to them. Disadvantaged group perspectives, too, may give excessive weight to some politically relevant information, to the exclusion of other information.

This qualification - that all social perspectives have both epistemic benefits and epistemic costs - once more accords with their emotional nature. Part of what explains the epistemic value of emotions, as I explained above, is that they are sources of salience. They put a spotlight on significant properties of the environment. But salience is a comparative matter: to highlight everything is to highlight nothing. Hence, insofar as emotions make some features of the environment salient, they also make other features less salient.

Consider again the anger Baldwin associates with being a black American in the 1960s. This anger highlights grave injustices that may otherwise have been overlooked. Yet, in doing so, it also makes other things less salient. In focusing people's attention on potential sources of injustice, for instance, anger makes them less attentive to evidence (when there is some) that others are not hostile or threatening. ${ }^{60}$ The more privileged the group, the greater the likely epistemic cost of this effect. The anger of middle-class white Americans may render salient concerns relating to decades of economic stagnation.

\footnotetext{
57 Philip Converse, "Religion and Politics: The 1960 Election," in Elections and the Political Order, ed. Angus Campbell et al. (New York: Wiley, 1966), 113.

58 Young, Inclusion and Democracy, 117.

${ }^{59}$ Cramer, The Politics of Resentment, 85-88, 140-144.

${ }^{60}$ Glen Pettigrove, “Meekness and 'Moral' Anger," Ethics 122 (2012): 341-370.
} 
However, in doing so, it makes them less likely to notice the greater economic obstacles faced by other groups, and more likely to see these out-groups (such as immigrants or minorities) as responsible for their economic concerns. ${ }^{61}$

Thus, this examination of the groups involved in group cognition leaves us with a challenge. Even if they possess epistemic value, social group perspectives also typically involve a countervailing epistemic cost. This cost is likely to be especially significant in the case of privileged perspectives. Though such perspectives reveal politically important group-specific constraints, they are liable to neglect even greater constraints relating to out-groups. When this happens, group cognition gives excessive weight to information stemming from one's group membership, relative to countervailing pieces of information. It risks, in short, leading to a dogmatic form of cognition.

More generally, the defense of group cognition I have offered so far points to two possible limitations. In 3.1, we noted that group-specific experiences and concerns may be epistemically irrelevant to some domains of political judgment (particularly ones that involve significant technical information). And we have just seen that even when they are relevant, they may dogmatically be given too much weight. The rest of this article considers these two concerns in turn.

\section{Technical Group Cognition}

\subsection{The Problem of Technical Group Cognition}

In some cases - cases of technical group cognition-group attachments profoundly influence people's judgments about technical descriptive matters that bear on political decisions. In 1988, for instance, Democrats were far less likely than Republicans to know that inflation had dropped since 1980. As for Republicans, they were far less likely to know, in 1996, that the deficit had decreased under the Clinton administration. ${ }^{62}$ The most striking examples, which I will focus on for the remainder of this section, concern scientific testimony about climate change. As Dan Kahan has shown, how far people accept testimony about climate science from a well-credentialed scientist depends significantly on their group attachments. Specifically, Republicans were less likely to judge that scientists' testimony was reliable if scientists said that anthropogenic climate change presented a high societal risk than if they said the opposite. The reverse was true for Democrats. ${ }^{63}$

These cases are distinctively troubling because group attachments, and the perspectives they define, seem irrelevant to assessing the truth of technical facts. According to Kahan, in letting their partisan attachments influence their judgments about technical facts, people are letting normative commitments affect their assessments of descriptive matters. So, technical group cognition involves fallaciously inferring an 'is' from an 'ought'. 64

One might respond that this objection is too quick. Recall that partisanship is driven by attachments to broader social groups, such as racial, gender, or regional groups. Furthermore, as discussed in 3.1, the perspective defined by social group attachments contains both descriptive and normative components: in particular, descriptive knowledge of certain social constraints, and normative commitments related to these constraints. Since group perspectives do involve descriptive commitments, relying on group

\footnotetext{
${ }^{61}$ See Maxime Lepoutre, "Rage Inside the Machine: Defending the Place of Anger in Democratic Speech," Politics, Philosophy, \& Economics 17 (2018): 415.

${ }^{62}$ Achen and Bartels, Democracy for Realists, 277-284.

${ }^{63}$ Kahan, "The Politically Motivated Reasoning Paradigm, Part 1," 4.

${ }^{64}$ Ibid., 1. See also Michael Lynch, Know-It-All Society (New York: Norton, 2019), 68-69.
} 
attachments to assess technical descriptive matters need not involve deriving an 'is' from an 'ought'.

This initial response is unsuccessful. Although group perspectives involve descriptive components, these components typically seem irrelevant to the technical matters at hand. For instance, the experiences that characterize rural life in America-e.g., rising joblessness - do not give rural Americans special insight into the reality of anthropogenic climate change. This stands in contrast to the cases examined in 3.1. The social experiences women disproportionately have, for example, do sometimes yield descriptive knowledge that is relevant to judgments about the reality of sexual harassment.

So, we are left with our original problem. In cases involving technical descriptive facts, group cognition purportedly lets the wrong kinds of reasons influence our judgments. Often, as Kahan maintains, it seems as though the normative concerns embedded in our group perspectives illicitly influence our views about politically relevant descriptive matters. Yet these normative concerns are irrelevant to assessing the truth or epistemic correctness of descriptive claims.

\subsection{The Relevance of Values to Descriptive Judgments}

In fact, normative concerns (e.g., 'joblessness is a pressing problem that needs addressing') can be relevant to assessing the truth or epistemic correctness of technical descriptive claims (e.g., 'anthropogenic climate change is real'). This, as we will see, does not mean that real-world cases of technical group cognition are always or even generally epistemically rational, all-things-considered. But it does mean that the above objection is insufficiently nuanced: group-based normative concerns can, under specific conditions, yield good epistemic grounds for accepting or rejecting testimony about technical matters.

To see why, consider that scientific hypotheses are typically underdetermined by evidence: as philosophers of science have long observed, the available evidence hardly ever suffices to fully confirm scientific hypotheses. ${ }^{65}$ The upshot of this uncertainty is that when scientists decide whether to assert that a scientific hypothesis $d$ is true, they need an epistemic standard for assertion: an account of how strong their evidence for $d$ must be to warrant asserting $d .^{66}$

How should this standard be determined? Epistemic values should of course play a major-and arguably the most important - role. That is, when deciding whether $d$ is sufficiently supported to warrant being asserted, scientists should consider how far it satisfies epistemic considerations of empirical adequacy, predictive precision, internal consistency, explanatory power, and so on.

Nevertheless, philosophers of science have increasingly argued that, alongside these epistemic values, nonepistemic considerations (such as moral and political concerns) also have a role to play in setting scientists' epistemic standards for assertion. ${ }^{67}$ For one thing, there are reasons to think that nonepistemic considerations are needed to set a specific epistemic standard: this, according to Daniel Steel, is because epistemic values often cannot uniquely determine what epistemic standard scientists should adopt. ${ }^{68}$ Moreover,

\footnotetext{
65 E.g., Imre Lakatos, "Falsification and the Methodology of Scientific Research Programmes," ed. Imre Lakatos and Alan Musgrave (Cambridge: Cambridge University Press, 1970), 91-196.

66 Stephen John, "From Social Values to P-Values," Journal of Applied Philosophy 34 (2017): 159-60; Heather Douglas, Science, Policy, and the Value-Free Ideal (Pittsburgh: University of Pittsburgh Press, 2009), chap. 5.

${ }^{67}$ For a comprehensive overview, see David Resnik and Kevin Elliott, "Value-entanglement and the integrity of scientific research," Studies in History and Philosophy of Science 75 (2019): 1-11.

68 Steel, "Epistemic Values and the Argument from Inductive Risk," Philosophy of Science 77 (2010): 2532.
} 
Heather Douglas has influentially suggested that scientists morally should take normative considerations into account when deciding how much evidence is enough. Testimony about politically relevant technical matters, Douglas notes, can have a significant social impact. Accordingly, when determining whether their evidence for $d$ is sufficient to warrant asserting $d$, responsible scientists should weigh the costs of false positives (asserting $d$ when it is false) against the costs of false negatives (not asserting $d$ when it is true). This weighing, in turn, necessarily relies on normative judgments about the value or disvalue of different outcomes. ${ }^{69}$

To illustrate, suppose scientist $\mathrm{A}$ is deciding whether to assert $d$ ('anthropogenic climate change is real'). When determining whether her evidence for $d$ is strong enough, A must clearly give significant weight to $d$ 's empirical adequacy, explanatory power, predictive precision, etc. Yet A should also consider the potential environmental damage that would result if climate change is real yet we fail to act against it, as well as the potential harmful effects of environmental regulation on certain jobs if climate change is false and we do act against it. How she weighs these respective considerations depends on how much she values environmental protection compared to job protection. If she values the former more strongly, she might judge that a false positive would be preferable to a false negative, and therefore adopt a lower epistemic standard for asserting $d$ than if she held opposite values.

Thus, while A's epistemic standard for asserting $d$ is constrained by epistemic values, it also depends partly on moral and political judgments. As we will see shortly, the constraints set by epistemic values can sometimes be very restrictive. But even if moral and political considerations exercise a weaker influence than epistemic values, the relevant point for now is that such considerations exercise some influence. This point, moreover, is not merely theoretical: scientists' judgments about technical matters (including climate change) do vary somewhat according to their moral and political orientations. $^{70}$

Now, if A's epistemic standard for asserting $d$ is influenced - among other thingsby A's normative judgments, then normative considerations are epistemically relevant to assessing A's testimony. Indeed, if A has incorrect normative commitments, this yields a pro tanto reason to believe that $\mathrm{A}$ is using an incorrect epistemic standard. Hence, if a listener B disagrees with A's normative judgments, this gives B a defeasible reason for doubting the epistemic reliability of A's testimony. ${ }^{71}$

Suppose, for example, that B comes from a rural community where jobs are scarce and, consequently, believes that one of the state's normative priorities should be creating jobs in economically deprived areas. Suppose, moreover, that environmental regulation would threaten key job-providing industries in rural areas. Since the stakes of environmental regulation are very high for B (given her normative concerns) it makes sense for her to adopt a relatively high epistemic standard for accepting claims asserting the reality of climate change. Suppose, finally, that scientist A is insensitive to the economic threat rural areas face - perhaps because this threat is less visible to A's social group than to B's. If so, then B has $a$ reason to believe that, because of this normative blindspot, A may have an insufficiently high epistemic standard for asserting $d$.

This reason, as I will explain in detail below, is defeasible. But even so, the preceding discussion is sufficient to establish that Kahan's objection to technical group cognition is

\footnotetext{
${ }^{69}$ Douglas, Science, Policy, and the Value-Free Ideal, chap. 4.

${ }^{70}$ E.g., Paul Slovic et al., "Intuitive Toxicology: Expert and Lay Judgments of Chemical Risks in Canada," Risk Analysis 15 (1995): 674; Tony Bolsen, James Druckman, and Fay Lomax Cook, “Citizens', Scientists', and Policy Advisors' Beliefs about Global Warming," Annals of the American Academy 658 (2015): 286.

${ }^{71}$ John, "From Social Values to P-Values," 160.
} 
overly hasty: normative considerations (such as those grounded in group-based perspectives) are in principle relevant to whether, epistemically speaking, one should accept claims about technical descriptive matters. ${ }^{72}$ Technical group cognition need not involve a conceptual fallacy.

Of course, there are also epistemically irrelevant ways in which group attachments might influence assessments of technical information. As discussed in 3.2, group perspectives often involve negative representations of out-groups, which fuel intergroup antipathy and distrust. This group-based animus can induce people to reject technical descriptive evidence simply because it comes from, or benefits, a resented out-group. Such a process lets epistemically irrelevant considerations (namely, intergroup dislike) affect assessments of technical evidence. And this, as Marc Hetherington and Thomas Rudolph have compellingly argued, is detrimental to democratic accountability. ${ }^{73}$ My point here is not that this cannot happen. Rather, in highlighting the epistemic relevance of group-based normative commitments to technical evidence, I am suggesting that technical group cognition is nonetheless not necessarily misguided. Accordingly, from the mere observation that people let their group attachments influence assessments of technical matters, one cannot immediately infer that they are engaging in epistemically wrongheaded conduct. ${ }^{74}$

Yet this conclusion must not be overstated. I have emphasized that the epistemic reasons supplied by group-based normative commitments are defeasible. Although group-based normative commitments can in principle yield some grounds not to defer to testimony about technical matters, listeners may nonetheless sometimes be epistemically required, all-things-considered, to defer. For group-based resistance to technical testimony to be epistemically apt, overall, at least three conditions must typically be satisfied: the influence of normative considerations on the testifier's epistemic standard must not be trivial relative to that of epistemic values; the testifier's normative commitments should differ substantially from the listener's; and the listener's groupbased normative concerns must not be deeply misguided. To clarify these three conditions, let us consider three scenarios where it would arguably be wrong, all-thingsconsidered, to reject technical descriptive claims because of one's group-based normative concerns.

The first scenario concerns the comparative influence of epistemic and nonepistemic considerations on the testifier's standard for assertion. As discussed above, epistemic values constrain the influence of moral and political considerations. Now, in some contexts, those constraints are highly restrictive. Indeed, as Stephen John has argued, the epistemic values of some scientific communities - and specifically, the International Panel on Climate Change (IPCC) - mandate epistemic standards that are extremely high. ${ }^{75}$ The IPCC, John notably observes, excludes relatively untested 'frontier science'

\footnotetext{
72 Ibid., 158.

${ }^{73}$ Marc Hetherington and Thomas Rudolph, Why Washington Won't Work (Chicago: Chicago University Press, 2015), 32-39, 74-95, 214-218.

${ }^{74}$ Some observations relating to technical group cognition in fact fit more easily with the optimistic interpretation I have offered than with the group-antipathy interpretation. For instance, Berinsky finds that Republicans and Democrats were more willing to believe a descriptive claim that supported a Democratic policy when it was voiced by a Republican. See Adam Berinsky, "Rumors and Health Care Reform," British Journal of Political Science 47 (2017): 258. This fits naturally with the account I have offered. When the speaker reports descriptive information that threatens her own party-based normative commitments, listeners have reason to believe that the speaker holds this information to a high epistemic standard. By contrast, from the perspective of the group-antipathy interpretation, it is puzzling why Democrats trust descriptive testimony that supports their cause more when it comes from a Republican than from a Democrat.

75 John, "From Social Values to P-Values," 167-168.
} 
and non-peer-reviewed evidence from its reports. ${ }^{76}$ So, although moral and political values may still exercise some influence over the IPCC's epistemic standards (as the above evidence that climate scientists' attitudes display some political patterning suggests) those standards cannot fall below a very high threshold. The upshot, for John, is that the IPCC's epistemic standards for assertion generally exceed those of nonscientists, even taking into account the high levels of evidence required by some nonscientists' normative commitments.

The broader point is this: when the testifier's epistemic values are so demanding that they severely limit the influence of normative judgments on their standards, listeners would usually be epistemically wrong, all-things-considered, not to defer to the testimony. ${ }^{77}$ Even though a listener's normative disagreement with the testifier can give her $a$ reason to think that the testifier has an excessively low epistemic standard-as in the earlier example of the rural inhabitant - that reason is likely to be overridden by the following countervailing consideration: that, given her stringent epistemic values, the testifier's standard must be very high. Accordingly, the testifier's epistemic standard is very likely to satisfy the listener's standard, notwithstanding their normative disagreement.

The second scenario relates to the content of the testifier's normative concerns. For the listener's group-based normative judgments to give her a reason to doubt the testifier's technical claims, the testifier's normative commitments must actually diverge from her own. After all, if the testifier and listener have identical normative judgments instead, then, from the listener's perspective, the fact that the testifier's normative concerns influence her epistemic standard provides a reason to think that the testifier has a correct standard.

This reveals another set of cases where listeners might be wrong, all-thingsconsidered, not to defer to testimony about technical matters. Sometimes, listeners mistakenly believe that the testifier's group-based normative commitments diverge from their own. For instance, conservative voters might believe that all climate scientists are extremely liberal, when in fact the scientist currently giving testimony has conservative leanings. In such a scenario, the listeners are liable to infer, erroneously, that this scientist's epistemic standard is lower than their own. And, consequently, they are liable to misguidedly reject the scientist's claims about climate change.

The third scenario concerns the listener's own normative commitments. In some cases, a listener's group-based normative judgments may be somewhat misguided or inaccurate. Now, if normative judgments are inaccurate, they constitute a misleading signal of what the right epistemic standard is: misguided normative judgments risk recommending a standard for accepting technical information that is either too high or too low. ${ }^{78}$ For example, if a group gives too much normative weight to job creation relative to environmental preservation, they risk adopting an epistemic standard for accepting evidence of climate change that is too high. Put differently, this group will be excessively resistant to evidence about climate change, given how good the evidence is and what the normative stakes at hand actually are.

Thus, we have a further kind of case where listeners would arguably be wrong to reject a scientist's testimony because of their group-based normative commitments. The

\footnotetext{
${ }^{76}$ Ibid., 166-67.

${ }^{77}$ Why usually, rather than always? Because, as John (ibid., 167) concedes, some normative commitments could conceivably induce the listener to adopt immensely high epistemic standards, which exceed even those mandated by the testifier's stringent epistemic values. The question in such cases, to which I turn below, is whether such normative commitments are themselves misguided.

${ }^{78}$ Ibid., 161.
} 
problem here is not necessarily that listeners fail to appreciate how stringent the testifier's epistemic values are. Indeed, John acknowledges that unusually extreme normative priorities can sometimes lead listeners to adopt epistemic standards that are even higher than the IPCC's very stringent standards.$^{79}$ Nor is the problem that listeners misjudge the content of the testifier's normative commitments. Rather, the problem here is that listeners' own epistemic standards are driven by deeply misguided group-based commitments. Hence, they risk being overly resistant to certain forms of technical evidence, and insufficiently resistant to others.

In sum, the lessons for technical group cognition are mixed. Contrary to what critics suggest, technical group cognition is not necessarily epistemically misguided. Given that moral and political commitments exercise some influence over the epistemic standards that guide testimony about technical descriptive matters, group-based normative judgments are epistemically relevant to assessing testifiers' epistemic standards. Yet technical group cognition may lead to overall epistemically bad behavior when group members start from incorrect judgments: for instance, if they are mistaken about what the testifier's normative concerns are, about the relative influence of those normative concerns on the testifier's epistemic standards, or about what normative concerns should be prioritized. When this happens, technical group cognition may lead people to be overly or insufficiently resistant, all-things-considered, to politically important technical information.

This problematic group-based dogmatism is of course not specific to the technical domain. It is a problem that we have already encountered when discussing the blindspots of social perspectives, particularly privileged perspectives, in 3.2. As we saw then, it arises more broadly because social perspectives typically yield partial or incomplete knowledge of society. Consequently, group cognition risks giving excessive weight to some descriptive and normative considerations (those that stem from people's groupbased experiences) and insufficient weight to others (those that run against people's group-based experiences). It is to this problem that I turn, finally, in the next section.

\section{Dogmatic Group Cognition}

\subsection{The Problem of Dogmatic Group Cognition}

Although group perspectives are in principle germane to politically relevant judgments, both technical and non-technical, we have shown in previous sections that such perspectives often involve epistemic blindspots. While a group's perspective yields important descriptive and normative information about the constraints encountered by that group, it characteristically involves far less information about out-groups and the constraints they face.

Because of this evidential bias, group cognition risks giving rise to a form of groupbased dogmatism. Relying on a skewed group perspective when assessing new evidence and claims may make people overly suspicious of, and resistant to, some information and claims (namely, those that jar with their group-based descriptive and normative commitments) and insufficiently critical of other information and claims (those that accord with their group-based descriptive and normative commitments).

To illustrate, recall an example introduced in 4.2. If rural communities witness job losses resulting from the regulation of polluting industries, but have little exposure to the environmental consequences of those industries, they may overprioritize job creation, relative to environmental preservation. This, in turn, might lead them to embrace

\footnotetext{
${ }^{79}$ See note 77 .
} 
excessively demanding standards for accepting evidence of climate change. The reverse might be said for urban communities. If, because of their partial experiences of social constraint, they give insufficient weight to job creation relative to environmental protection, they may become overly resistant to evidence that some areas depend on polluting industries for their economic survival.

As discussed in 3.2, this problem is particularly salient with privileged groups, because the constraints these groups are likely to overlook may be even more pressing than the ones they have distinctive access to. If a middle-class couple have daily experiences of struggling to finance their children's college education, but little experience of the poverty faced by more disadvantaged groups, they may end up being more concerned about the former challenge than the latter. Accordingly, they may adopt an excessively demanding standard for accepting evidence that redistributive taxation from middle-class to working-class households is needed.

Thus, when group perspectives involve significant blindspots as well as significant epistemic insights, group cognition may lead to dogmatism. If, as 3.2 suggested, such cases of dogmatic group cognition are common, or if they affect pressing political issues (such as climate change), then group cognition might after all seem to undermine democratic accountability.

\subsection{The Systemic Role of Dogmatic Group Cognition}

This worry is nevertheless too hasty. As I will now show, dogma can in fact be epistemically fruitful when considered from a broader, systemic, perspective. By implication, even dogmatic forms of group cognition can, under the right conditions, contribute positively to the democratic ideal.

The insight that dogmatism can be epistemically fruitful is most familiar from, and has been most extensively developed within, philosophical examinations of scientific progress. The starting point for this insight, Imre Lakatos has influentially argued, is that the balance of existing evidence is not always a good indicator of which scientific theories are best. ${ }^{80}$ Many scientific theories that eventually proved superior to their competitors previously faced numerous counterexamples and were comparatively poorly supported by the evidence.

Take Prout's hypothesis that the atomic weights of all pure chemical elements are whole numbers. When it first appeared, it was widely inconsistent with existing scientific evidence. Proutians nevertheless refused to reject it. Instead, they hypothesized that the abundant anomalies were due to faulty experimental techniques. Only a century later, when Proutians had tirelessly revolutionized chemistry's experimental techniques, was Prout's theory finally widely acknowledged as superior. ${ }^{81}$

Crucially, according to Lakatos, this instance of scientific progress was enabled by Proutians' dogmatism: they stubbornly kept their theory despite its glaring inconsistency with the balance of existing evidence; they assumed that these anomalies indicated a problem with experimental methods, not with their theory; and they did so even though they did not yet have the analytical tools needed to support this assumption. ${ }^{82}$

Generalizing from such historical episodes, Lakatos concludes that scientific investigation is most productive when many rival research programs dogmatically defend their core hypotheses. Scientists within a research program, Lakatos insists, should follow a "negative heuristic": a rule that forbids them from taking countervailing evidence as a

\footnotetext{
${ }^{80}$ Lakatos, "Falsification and the Methodology of Scientific Research Programmes."

${ }^{81}$ Ibid., 138-154.

${ }^{82}$ Ibid.
} 
sign that the basic tenets (or "hard core") of their program are false, and instead requires them to refine their auxiliary hypotheses (say, hypotheses about experimental techniques) to explain this evidence away. Thus, the negative heuristic requires scientists to commit dogmatically to the hard core. They strongly discount countervailing data until they can account for it in a way that preserves their core hypotheses. Lakatos is explicit about this: he overtly praises "the dogmatic attitude of sticking to a theory as long as possible". ${ }^{83}$

While this dogmatism seems irrational at an individual level-indeed, it requires scientists to strongly discount countervailing evidence-Lakatos's point is that it is fruitful at a broader, systemic level. When many scientists dogmatically pursue competing theories, this allows the scientific community to refine and test many theories at once. Hence, the community minimizes the risk of prematurely abandoning superior yet under-supported theories.

Using formal modelling techniques, Kevin Zollman has recently refined Lakatos's thesis. Like Lakatos, Zollman finds that "endowing individuals with dogmatic priors has a good effect when the overall behavior of the community is in focus." 84 An epistemic system with dogmatic agents is less likely to prematurely discard superior theories, and more likely to eventually widely embrace superior theories. Yet, crucially, Zollman finds that this benefit occurs only if the information yielded by different scientists' investigations circulates widely between them. By contrast, when dogmatism is paired with low circulation of information, it impairs the system's epistemic productivity. ${ }^{85} \mathrm{In}$ these cases, scientists fail to arrive at a consensus on superior theories, even after the community has had ample opportunity to test multiple theories' promise.

Thus, the scientific case underscores the following conclusion. Provided that certain background conditions are satisfied-namely, that information circulates widely across the community-dogmatism needn't impede epistemically fruitful inquiry. Even if dogmatism is irrational at an individual level, the competition of multiple dogmatic groups can stimulate epistemic progress at a systemic level.

We can carry this conclusion over to the case of dogmatic group cognition. Even if dogmatically upholding the descriptive and normative components of one's group perspective seems an epistemically defective way for individuals to form political judgments, it does not necessarily follow that this impairs the epistemic fruitfulness of the broader democratic process. The competition of multiple dogmatic social groups may, like the competition of dogmatic scientific groups, be epistemically beneficial.

More specifically, a democratic community composed of many social groups, each of which defends its starting commitments with some (non-absolute) degree of dogmatism, is liable to generate more varied information that is relevant to political judgment. Rural inhabitants who overprioritize job creation will be more disposed to uncover evidence of how environmental regulation harms rural jobs. And because, as discussed earlier, they hold evidence of climate change to excessively high epistemic standards, their scrutiny may contribute to revealing limitations of the evidence produced by climate science. Conversely, environmentalists may, because of their contrasting epistemic standards, be

\footnotetext{
${ }^{83}$ Ibid., 177.

${ }^{84}$ Kevin Zollman, "The Epistemic Benefits of Transient Diversity,” Erkenntnis 72 (2010): 33.

${ }^{85}$ Ibid., 31-33. A related condition is that the dogmatic agents in the epistemic system must not be absolutely dogmatic. They must give some non-trivial epistemic weight to countervailing evidence, such that a sufficiently large quantity of it could potentially sway them. Otherwise, theories that prove superior over time could never gain the assent of dogmatic agents. This success condition is related to the 'circulation of information' condition: if agents dismiss countervailing information offhand, giving it no consideration or weight whatsoever, then the information has not genuinely circulated between them in any meaningful sense. Thus, I return to this concern below, when discussing how the circulation of information condition might fail.
} 
more effective at finding flaws in evidence that environmental regulation harms jobs and more likely to generate new evidence of climate change.

A similar observation extends to privileged groups. Consider again middle-class adults who overprioritize the economic difficulties that their group faces. Because of their attending resistance to the idea of redistributive taxation towards working-class groups, they are more disposed to uncover evidence of problems posed by such policies. They may, for instance, unearth new evidence of the burdens such policies impose on the middle class, or of the negative impact (if there is one) such policies might have on economic growth. While the countervailing benefits of redistributive taxation highlighted by the perspectives of disadvantaged groups may well outweigh these problems, evidence of such problems is relevant to identifying the best possible policy. Thus, from a systemic perspective, even privileged group perspectives that suffer from serious blindspots may play a fruitful complementary role.

To reiterate, this systemic role of dogmatic group cognition parallels the scientific case. Scientists who dogmatically pursue different research programs stimulate scientific progress, in part, by unearthing different and conflicting evidence. Analogously, different dogmatic social groups can fruitfully complement one another in the democratic system by unearthing different pieces of politically relevant information.

We should not overstate this conclusion. Individual-level dogmatism, recall, improves the epistemic system's productivity only when the information each agent generates circulates readily to others. Accordingly, dogmatic group cognition can gradually contribute to improved political judgments, but only when different groups widely share the different information they generate. When they do not, the benefits of dogmatic group cognition fail adequately to impact people's judgments: a more varied body of politically relevant information is produced, but never pooled.

This qualified conclusion resonates with an influential strand of democratic theory: the systemic approach to democratic deliberation. According to this tradition, wideranging deliberation among citizens is normatively central to democracy. But such deliberation does not occur in a single all-encompassing arena. Instead, the deliberative ideal is realized in a system composed of many deliberative arenas which have different constituencies. $^{86}$

Because they have different constituencies, Mansbridge suggests, these different arenas typically operate under different working assumptions. An all-women consciousness-raising group, a town-hall meeting in rural Wisconsin, and a political party conference take different experiences and concerns for granted. These divergent assumptions are not critically scrutinized by the relevant deliberating group, and instead serve as a premise for deliberation. ${ }^{87}$

Although different deliberative spheres have different constituencies and different working assumptions, proponents of the systemic approach emphasize that they must nevertheless remain sufficiently closely connected to one another. Mansbridge warns against letting "parts of the deliberative system become decoupled in the sense that good reasons arising from one part fail to penetrate the others". ${ }^{88}$ The point is that, once deliberation within an arena yields new insights, this information should be shared with other arenas. Only then can the deliberative system be truly epistemically fruitful.

Thus, the systemic ideal advocates discussion among different groups, where these groups uncritically accept different assumptions, provided that they communicate the

\footnotetext{
${ }^{86}$ Jane Mansbridge et al., "A Systemic Approach to Deliberative Democracy," in Deliberative Systems, ed. John Parkinson and Jane Mansbridge (Cambridge: Cambridge University Press, 2012), 1-26.

${ }^{87}$ Ibid., 7.

${ }^{88}$ Ibid., 23.
} 
results of their discussions to one another. This closely resembles our conclusion: that dogmatically exploring one's group perspective can play a valuable role in the broader system, provided that the information which emerges from this exploration circulates widely between different groups. This consonance matters, because it shows that critics of the democratic ideal are wrong on two counts: not only do they mistakenly hold that dogmatic group cognition necessarily impairs the process whereby people form political judgments, but they misleadingly suggest that democratic theory is insensitive to this phenomenon. Far from being insensitive to the reality of dogmatic group cognition, normative democratic theory helps to specify the conditions under which it can be epistemically productive.

The point so far has been that dogmatic group cognition can be reconciled with the democratic ideal. But this does not mean that this phenomenon poses no problem for actual democracies. On the contrary, by suggesting that dogmatic group cognition is acceptable provided that information circulates freely between different groups, the systemic ideal helps identify more precisely what goes wrong in actual political discourse. The problem is that contemporary democracies involve dogmatic group cognition and a lack of intergroup communication.

There are two related reasons for this lack of intergroup communication, both of which we have encountered in previous sections. First, different groups often live segregated lives: they inhabit different regions or neighborhoods, occupy different jobs, belong to different social media enclaves, and consult different news outlets. Hence, they have little contact with one another. ${ }^{89}$

Second, contemporary democracies involve substantial intergroup dislike and distrust (or 'affective polarization'). Therefore, people from different groups may refuse to speak to each other when their paths do meet. ${ }^{90}$ And even when they do speak, mutual antipathy might still keep information from genuinely circulating between them. Indeed, such antipathy might lead them to simply dismiss, and give no weight whatsoever to, the information contained in out-group perspectives. Now, Zollman's formal analysis of dogmatism in epistemic systems indicates that agents do not need to be fully open to countervailing perspectives: as discussed earlier, they may significantly discount the weight of countervailing information. Nevertheless, a bare minimum for information to count as circulating between agents is that they at least consider, or give some non-trivial weight to, countervailing information. ${ }^{91}$ But mutual antipathy might keep them from doing so.

These two conditions are causally interrelated. Thoroughgoing segregation, Anderson has argued, plays a central role in explaining why different groups come to dislike each other. Segregation leads to infrequent contact with outgroups, which induces people to underestimate the challenges out-groups face, to misattribute instances of bad behavior to their essential dispositions, and to regard deviant members of out-groups as representative of the whole group. ${ }^{92}$ Segregation thus crucially facilitates intergroup dislike. In turn, mutual dislike induces different groups to avoid each other and thereby self-segregate. ${ }^{93}$

The result is a problematic fragmentation of the public sphere. Because different groups inhabit separate spheres, and because they are reluctant to speak and engage with one another, they fail to pool the insights and arguments that they independently generate.

\footnotetext{
${ }^{89}$ Anderson, The Imperative of Integration, chaps. 4-5.

${ }^{90}$ Cramer, The Politics of Resentment, 2-3.

${ }^{91}$ See note 85 for further discussion.

92 Anderson, The Imperative of Integration, 46-47.

${ }^{93}$ Ibid., 67-75.
} 
We end up with the unhealthy combination that philosophers of science discourage: dogmatism and low circulation of information.

This diagnosis has a crucial upshot. It renders more tractable the problem that group cognition poses for actual democracies. What makes the problem of group cognition so daunting, as noted in Section 2, is that it stems from dispositions that are deeply embedded in human psychology. Accordingly, it seems as though saving democracy would require, as Achen and Bartels claim, "a radical change in human nature". ${ }^{94}$ But once we appreciate that the problem is not (dogmatic) group cognition per se, but rather its contingent conjunction with a fragmented public sphere, alternative remedies come into view. Notably, we can strive to de-fragment public discourse, by tackling the segregation and affective polarization that obstruct intergroup communication. Doing so is difficult, to be sure. But it does not involve altering human nature itself.

Instead, it can partly be achieved by altering the institutional conditions that underpin intergroup segregation. To this end, Anderson recommends numerous policies, such as redrawing political districts to make them less homogenous; incentivizing the creation of diverse neighborhoods; promoting intergroup integration within schools; encouraging news stories to include links to opposing coverage of the same stories; adopting aggressive affirmative action policies, and so on. ${ }^{95}$ Given the causal connection between segregation and intergroup dislike, the point of such integrative policies is twofold: by tackling segregation, they also help mitigate the affective polarization that prevents intergroup communication. When structured appropriately, Anderson explains, sustained intergroup contact can disrupt the formation of negative attitudes toward out-groups, and thus make groups more willing to engage with each another. ${ }^{96}$

Situating dogmatic group cognition in a broader democratic system, by analogy with scientific practice, is therefore helpful in several ways: it reveals that dogmatic group cognition is not inherently epistemically problematic for political judgment; it highlights the auxiliary social conditions that can nevertheless make it so; and, consequently, it highlights tractable strategies for addressing the real-world difficulties created by dogmatic group cognition. Furthermore, this systemic view of dogmatic group cognition is wholly consonant with the systemic approach to democratic deliberation. So, normative democratic theory can guide us in realizing the conditions that make dogmatic group cognition work for democracy.

\section{Conclusion}

Group cognition, I have argued, need not be opposed to democratic accountability, even when it takes a technical or somewhat dogmatic form: under the right conditions, group perspectives can play a fruitful epistemic role in the broader democratic system. Yet we have also seen that the requisite conditions sometimes fail to obtain. When this happens, group cognition risks impairing real-world democratic decision-making. Thus, though the deep-seated influence of group identity in human psychology does not in itself threaten democracy, its pairing with infelicitous social conditions may.

This diagnosis has a vital normative payoff. If saving democracy required altering deep-seated features of human psychology, doing so might seem impossible. Instead, however, we can target the conditions that divert group cognition from its positive

\footnotetext{
${ }^{94}$ Achen and Bartels, Democracy for Realists, 10.

95 Anderson, The Imperative of Integration, chaps. 6-7; Anderson, "Democracy, Public Policy, and Lay Assessments of Scientific Testimony," 158.

${ }^{96}$ Anderson, The Imperative of Integration, 123-127.
} 
potential. In particular, we should tackle the thoroughgoing segregation that keeps different groups apart and sustains intergroup antipathy. Though arduous, this task is more tractable than the alternative: it targets, not built-in features of human cognition, but social arrangements that are ultimately contingent. 